\title{
UM NOVO MÉTODO DE ANÁLISE VOCAL ATRAVÉS DA TERMOMETRIA DA FALA: ESPERANÇA DE DIAGNÓSTICO PRECOCE DE LESÕES DAS PREGAS VOCAIS ?
}

\author{
Guilherme F. Gomes ${ }^{1}$, Evaldo D. M. Filho ${ }^{1}$, José Viriato Coelho Vargas ${ }^{2}$ \\ ${ }^{1}$ Serviço de Endoscopia do Hospital Nossa Senhora das Graças - Curitiba - PR \\ ${ }^{2}$ Departamento de Mecânica da Universidade Federal do Paraná - Curitiba - PR
}

\section{INTRODUÇÃO}

Fm recente revisão sobre avaliação instrumental da voz, BEHLAU (1997) relatou que o incremento das pesquisas e o rápido desenvolvimento de novas tecnologias, em especial nos últimos 20 anos, afetaram de modo profundo a análise vocal. Houve também profundo impacto na laringologia moderna com a introdução e o emprego rotineiro dos endoscópios, que proporcionaram verdadeira revolução no diagnóstico dos problemas das pregas vocais e da laringe.

A mesma autora relatou que atualmente as pesquisas estão principalmente centralizadas na análise rápida e confiável da voz humana, e que o uso de novos aparelhos permitiu que a produção de dados sobre a função fonatória crescesse em progressão geométrica. $\mathrm{O}$ conhecimento das implicações e o efeito de toda essa informação no comportamento fonatório e consequentemente na configuração de um programa de reabilitação vocal ainda não existe, e o impacto dessas informações ao alcance das mãos muito contribuirá não somente para as atividades como clínicos da voz mas também para a melhoria do perfil profissional.

Ainda nesta revisão, a autora relatou que o acúmulo de informações obtidas por análises vocais laboratoriais pode ser considerado massacrante, porém, quando associadas a dados clínicos e avaliações da função laríngea, possibilitam ao pesquisador informaçôes cruciais sobre a fisiologia laríngea e, sobretudo, sobre as mudanças fisiológicas produzidas no comportamento vocal do paciente. Portanto, dados e informações obtidas através de laboratórios de voz são de fundamental importância.

HIRANO E BLESS (1997) relataram que muitos otorrinolaringologistas e fonoaudiólogos estão convictos de que o ouvido e o espelho laríngeo são as únicas ferramentas necessárias para uma adequada análise vocal, descartando a utilização da avaliação vocal objetiva através dos modernos instrumentos e laboratórios de voz disponíveis atualmente. Essa antiga e secular rejeição a todo e qualquer processo de quantificação de vozes cede lugar à nova perspectiva profissional, que envolve uma prática tecnológica confiável, capaz de ser arquivada e reproduzida inúmeras vezes. Também não se deve crer piamente que a solução para a avaliação e reabilitação das disfonias esteja nos computadores.

A voz é um fenômeno complexo que exige diversas medidas para a descrição de suas características porque inúmeras grandezas físicas estão envolvidas na sua produção. Os vários equipamentos existentes para análise vocal medem: vibração das pregas vocais, fluxo aéreo glótico, volume do ar que passa através das pregas vocais, pressão subglótica, área de contato da mucosa das pregas vocais e sinal sonoro vocal. Após a entrevista do falante, observação e descrição de sua voz, dados obtidos do laboratório de voz devem ser integrados à análise vocal para proporcionar avaliação vocal completa. As medidas de análise vocal encaixam-se como peças de um quebra-cabeças, cada qual levando à conexão natural da peça seguinte e, juntas, fornecem um quadro que não pode ser visualizado com dados somente de uma das peças.

Nenhum método instrumental de análise vocal consegue 
fornecer todas as informações da fisiologia e fisiopatologia vocal, que são importantes para o diagnóstico e manejo dos problemas vocais. READ (1992) relatou que o número de sistemas de avaliação da voz humana disponíveis já é bastante grande e cada um deles apresenta vantagens e desvantagens, não existindo nenhum sistema perfeito e insubstituível capaz de realizar avaliação vocal completa. Novos estudos e instrumentos que avaliem a função da laringe devem ser testados e desenvolvidos para o melhor entendimento e aprimoramento do seu produto : a voz humana.

Este artigo relata o uso de um novo instrumento de análise vocal baseado na aplicação de fundamentos da transferência de calor, fenômeno físico jamais explorado anteriormente na análise da produção da voz. Através da distribuição de temperatura na cavidade oral, o método explora diferenças entre o padrão de fluxo aéreo e o fechamento das pregas vocais de indivíduos com voz normal e tem potencial para utilização em indivíduos disfônicos para a detecção de doenças precoces das pregas vocais.

\section{EQUIPAMENTO DE TERMOMETRIA DA FALA}

$O$ aparelho de termometria da fala consiste de um tubo de alumínio, circundado por uma camisa cilíndrica através da qual instalou-se um fluxo de água corrente. Todo o aparelho foi montado em uma mesa horizontal. Uma haste metálica para instrumentação foi colocada no centro do tubo, como mostra a parte inferior da Fig. 1. Oito sensores térmicos de alta precisão do tipo YSI44004, Bead I, com o diâmetro máximo de $2.4 \mathrm{~mm}$, foram colados à haste metálica no interior do tubo, utilizando epóxi de alta condutividade térmica, e posicionados a $1,2,3,4,5,7,5,9$ e $11 \mathrm{~cm}$ a partir da entrada do tubo.

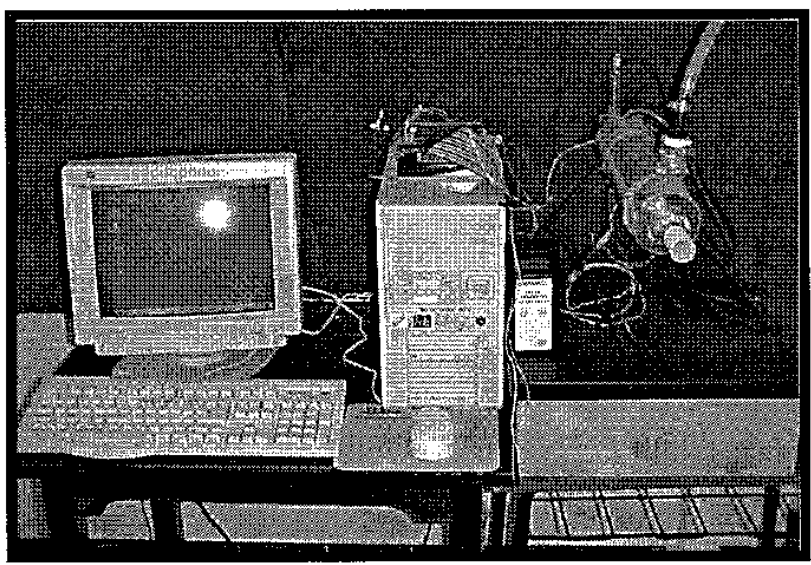

Fig. 1 - Aparelho de termometria da fala

Um sensor térmico foi posicionado na parede do tubo para medição da temperatura da parede do tubo, e o mesmo foi revestido por isolante térmico para não sofrer influência da temperatura ambiental externa.

Os oito primeiros sensores térmicos têm por finalidade a medição instantânea da distribuição da temperatura ao longo do centro do tubo e dessa maneira foi possível avaliar o perfil da temperatura durante a fonação do indivíduo em teste, na saída da cavidade oral.

Adesivo epóxi de alta condutividade e à prova de água foi utilizado para fixar os sensores térmicos à haste metálica de instrumentação.

As medições de temperatura provenientes dos sensores térmicos são realizados com um sistema de aquisições de dados computacional, consistindo de uma placa A/D AX5810 (Axion Technology Co. Ltd.), uma placa multiplexadora AX758 (Axion Technology Co. Ltd.), de dezesseis canais. Os dados provenientes da placa AX5810 são processados por um programa de linguagem $\mathrm{C}$ para transformá-los em valores numéricos de temperatura em graus Celsius. Desta maneira, as medidas provenientes dos dez termistores são realizadas dentro de um mesmo segundo. O programa também gera arquivos dos dados numéricos medidos para cada pacientes, para posterior processamento gráfico.

\section{RESULTADOS INICIAIS}

GOMES E VARGAS realizaram um estudo com o aparelho de termometria da fala e testaram 30 indivíduos do sexo masculino e 30 indivíduos do sexo feminino. Cada indivíduo em teste produziu a vogal sustentada /e/ através de um bocal estéril conectado à parte anterior do aparelho já descrito anteriormente, emitida na frequiência e intensidade habituais do falante. Cada indivíduo realizou o teste por três vezes.

A duração da fonação no teste foi estabelecida como de cinco segundos. O critério para a definição deste tempo de fonação foi simplesmente o de proporcionar uma situação confortável ao indivíduo em teste, ao mesmo tempo permitindo que o sensor realizasse uma medida o mais precisa possível do escoamento de ar na saída da cavidade oral durante a fonação. De acordo com o fabricante dos termistores (YSI, Inc.), o tempo necessário pelo termistor para a medição de uma nova temperatura é de menos de um segundo quando submetido a uma variação de até $2000 \mathrm{C}$.

A leitura dos valores das temperaturas nos sensores térmicos foi realizada pelo computador cinco segundos após o início da fonação automaticamente, valor este ajustado no programa de aquisição de dados em linguagem $\mathrm{C}$, escrito especificamente para estes testes.

Estabeleceu-se um intervalo de três minutos após o término de uma coleta de dados e o início de outra, para estabilização dos sensores térmicos, e consequente restabelecimento da mesma condição inicial para todos os testes. A Figura 2 mostra um indivíduo testado neste experimento, durante a realização da vogal sustentada /e/.

Os resultados deste estudo mostraram que todos os indivíduos apresentaram queda do valor de temperatura em relação à posição dos sensores térmicos ao longo do tubo, antecipando a possibilidade de obtenção de uma curva média para todo o grupo. Foi possível também classificar homens e mulheres em faixas normatizadas para a distribuição de temperatura na saída da cavidade oral. As faixas padronizadas para os homens foi claramente distinta da faixa para mulheres. As temperaturas no grupo de homens foram sempre maiores do que as temperaturas no grupo de mulheres.

Os autores deste estudo concluíram que o aparelho de termometria da fala era confiável a ser utilizado como instrumento de análise vocal e de que foi possível padronizar dentro de faixas restritas, curvas normalizadas para a distribuição de temperatura na saída da cavidade oral, para indivíduos do sexo masculino e feminino. Estas curvas têm o 
potencial de serem utilizadas em estudos futuros para comparação com indivíduos com doenças de pregas vocais.Os autores deste estudo concluíram que o aparelho de termometria da fala era confiável a ser utilizado como instrumento de análise vocal e de que foi possível padronizar dentro de faixas restritas, curvas normalizadas para a distribuição de temperatura na saída da cavidade oral, para indivíduos do sexo masculino e feminino. Estas curvas têm o potencial de serem utilizadas em estudos futuros para comparação com indivíduos com doenças de pregas vocais.

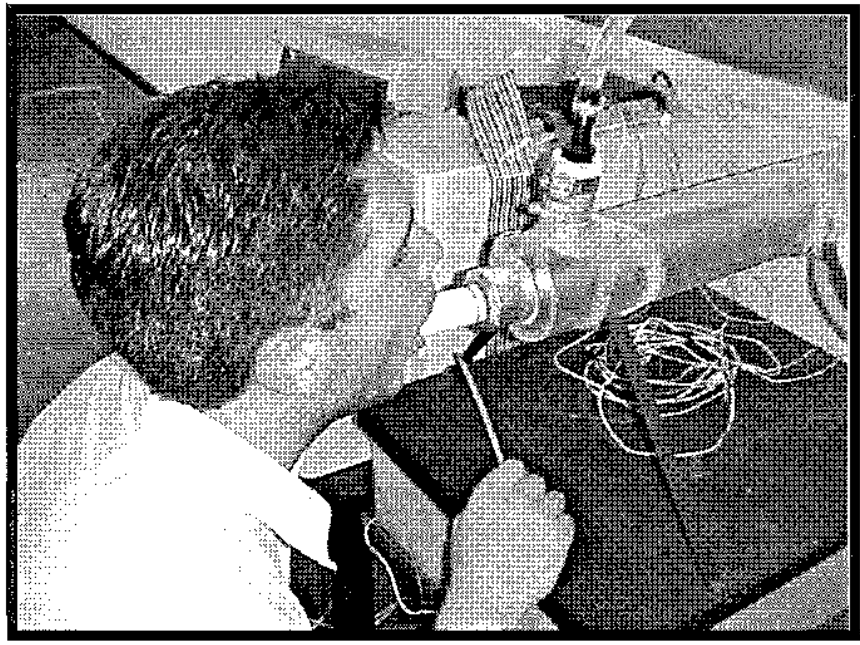

Fig. 2 - Indivíduo em posição durante a realização do teste de fonação

\section{POTENCIALIDADE DO APARELHO DE TERMOMETRIA DA FALA NO DIAGNÓSTICO DE LESÕES DAS PREGAS VOCAIS}

Os indivíduos com padrão de voz soprosa apresentam fechamento glótico incompleto durante a fonação, e o pico médio do fluxo aéreo glótico é maior do que a média dos indivíduos com voz normal e fechamento glótico completo. Estudos prévios realizados com medidas do fluxo aéreo já demonstraram que pacientes disfônicos com fechamento glótico incompleto apresentaram fluxo aéreo glótico maior. Entretanto, o nível de precisão dos termistores é maior do que os instrumentos utilizados para a medida do fluxo aéreo (anemômetro, pneumotacógrafos e sistemas de Venturi), e portanto pequenas alterações das pregas vocais com pequenos fechamentos glóticos incompletos, não seriam detectados pelos instrumentos de medida do fluxo aéreo, mas espera-se que sejam detectados pelos termistores de alta precisão .

Desta maneira, pode-se selecionar a priori indivíduos candidatos ou não à realização de um exame invasivo. Caso, no exame proposto neste estudo, o indivíduo se situar nas faixas de normalidade, pretende-se não recomendá-lo para um exame invasivo. Por outro lado, se o indivíduo se situar fora da faixa de normalidade aqui apresentada, pretende-se recomendá-1o para um exame diagnóstico de imagem. Essa abordagem de triagem citada acima, pode ser utilizada em grupos de indivíduos que fazem uso profissional da voz, como por exemplo, em professores da rede municipal e estadual. cantores, atores e jornalistas, para detecção de problemas precoces das pregas vocais. Uma segunda indicação do uso da termometria da fala é nos pacientes disfônicos, como um novo parâmetro de análise vocal objetiva, que juntamente com outros métodos, propicia dados para avaliação vocal global.

\section{REFERÊNCIAS}

BEHLAU,M. Considerações sobre a análise vocal emlaboratórios computadorizados de voz. In : ARAÚJO, R.B.; PRACOWINIK, A.; SOARES, L.S.D. Fonoaudiologia Atual. São Paulo : Revinter, 1997. P.93-115.

HIRANO,M.; BLESS, D. Exame videoestroboscópico da laringe. Porto Alegre : Artes Médicas, 1997.
READ, C. ; BUDER, E.H.; KENT, R.D. Speech analysis systems : an evaluation. J.Speech HearRes., Rockville, v.35, p.314-332, Apr. 1992.

GOMES ,G.F. O emprego da distribuição da temperatura na saída da cavidade oral como novo parâmetro de análise vocal. Dissertação apresentada na Clínica Cirúrgica da UFPr. Curitiba, 1998. 